Background Preterm infants at term equivalent age are smaller than full term infants with a higher fat mass. The aim of this study was to determine if alterations in adiposity are already evident at 32-36 weeks corrected age (CA).

Methods Preterm babies $(n=21)$ born before 32 weeks gestation were studied between 32 and 36 weeks CA using the PEAPOD Infant Body Composition System to assess \% body fat. The data were compared with a second group of babies $(n=17)$ born at 32-36 weeks gestation.

Results Mean \% body fat at 32-36w CA in infants born < 32w was $14.1 \pm 5.8$ (mean \pm SD) and this was significantly higher than $\%$ body fat in infants born at 32-36 weeks $(7.9 \pm 4.5, \mathrm{P}<0.01)$. Mean \% body fat at 32-36 weeks in infants born $<32 \mathrm{w}$ was also significantly higher than \% fat at birth in infants born at term $(10.1 \pm 4.1, \mathrm{P}<0.05)$. \% body fat in infants born $<32 \mathrm{w}$ was positively correlated $(\mathrm{R}=0.59, \mathrm{P}<0.05)$ with post-natal age at measurement suggesting that longer periods of ex utero nutrition result in greater increases on \% body fat. \% body fat in infants born $<32 \mathrm{w}$ was also positively correlated with weight at the time of measurement $(R=0.56, P<0.01)$ and there was a tendency for those babies who had gained weight most rapidly since birth to have higher \% fat.

Conclusion \% body fat in infants born $<32$ weeks is elevated by 32-36 weeks CA.

\section{EARLY FORMATION OF PHOTOISOMERS DURING PHOTOTHERAPY IS NOT SIGNIFICANTLY ENHANCED BY INCREASING IRRADIANCE OR EMPLOYING PHOTODIODE LIGHTS}

doi:10.1136/archdischild-2012-302724.1348

${ }^{1} \mathrm{~K}$ Mreihil, ${ }^{2 \mathrm{P}}$ Madsen, ${ }^{1,3} \mathrm{~B}$ Nakstad, ${ }^{4} \mathrm{~F}$ Ebbesen, ${ }^{3,5} \mathrm{TW}$ R Hansen. 'Barne- og Ungdomsklinikken, Akershus University Hospital, Lørenskog, Norway; ${ }^{2}$ Pediatrics, Aalborg Sygehus Nord, Aalborg, Denmark; ${ }^{3}$ Faculty of Medicine, University of Oslo, Oslo University Hospital, Oslo, Norway; ${ }^{4}$ Pediatrics, Aalborg Sygehus Nord, Faculty of Medicine, University of Aarhus, Aalborg, Denmark: ${ }^{5}$ Kvinne- og Barne Klinikken, Oslo University Hospital Rikshospitalet, Oslo, Norway

Background Phototherapy is the mainstain of treatment for neonatal jaundice. Photoisomers are more polar than native bilirubin IX-alpha $(z, z)$ and can be excretedinbileandurine without conjugation. Rapid formation of PI may be an important component of the crash-cartapproach to extreme NJ.

Objective To compare the rate and degree of photoisomerization during intensive phototherapy using single or double banks of fluorescent lights vs a single bank of photodiodes.

Design and methods: The study was approved by the regional research ethics committee. 42 newborn infants due to receive phototherapy for $\mathrm{NJ}$ according to Norwegian national guidelines. Enrolled by written informed consent from the parents. Infants were randomly to one of 3 groups:

i. single unit phototherapy with fluorescent lights

ii. double unit fluorescent phototherapy;

iii. single unit photodiode. Irradiance was measured on the back and flanks.

Blood was drawn at $0,15,30,60,120$, and240 minutes. Total serum bilirubin was analyzed by cooximetry. Serum samples were frozen and analyzed for photoisomers by HPLC. Data were analyzed using Anova and t-tests.

Results Irradiance was significantly higher using double fluorescent lights vs single fluorescent and photodiodes (40.4 p<0.05 for double vs single fluorescent and single photodiodes, measured on the back). 2-way Anova was highly significant for increase of PI over time $(p<0.0001)$, and significant for group differences $(p<0.05)$.

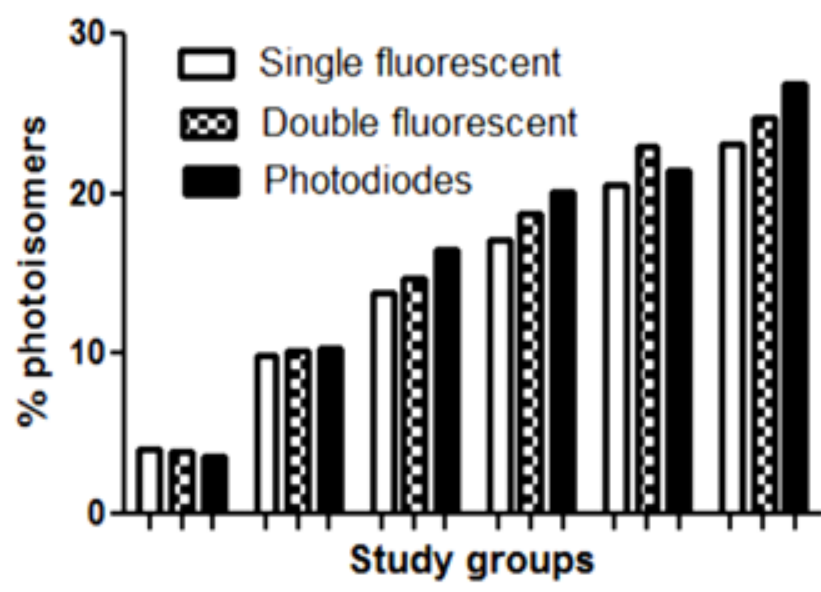

Abstract 1348 Figure 1 Study Groups

Formation of PI reached $25 \%$ at $4 \mathrm{~h}$, anddid not appear to have plateaued.

Conclusions Formation of PI is rapid during intensive phototherapy. However, increasing irradiance or chancing the character of thelight source did not significantly improve the rate or level of PI formation.

\section{TREATING INFANTS OF VITAMIN D DEFICIENT MOTHERS - IS ROUTINE SUPPLEMENTATION WITH ABIDEC ALONE SUFFICIENT}

doi:10.1136/archdischild-2012-302724.1349

A Rakhecha, K Ganesan. Department of Neonatology, St Mary's Hospital, Central Manchester University Hospitals, Manchester, UK

Background and Aims Infants with maternal vitamin D deficiency are at increased risk of low vitamin D levels. Cholecalciferol is the usual treatment for such infants. We wanted to see whether routine vitamin supplementation with Abidec alone was enough to normalize vitamin $\mathrm{D}$ levels in such infants.

Methods All infants infants with maternal vitamin $\mathrm{D}$ deficiency, after August 2011 were given $0.6 \mathrm{ml}$ Abidec which provides $400 \mathrm{IU}$ of vitamin D2. Vitamin D levels were done at birth and infants with borderline $(10-20 \mathrm{ng} / \mathrm{dl})$ or deficient $(<10 \mathrm{ng} / \mathrm{dl})$ vitamin $\mathrm{D}$ levels had repeat test at follow-up. Records of all such infants, from August to November 2011 were reviewed. The results were also compared to the period when cholecaciferol was used.

Results Total 64 patients were identified. Initial vitamin D results were obtained for 60 infants of which 16 infants were deficient (range 3.1 to $9.1 \mathrm{ng} / \mathrm{dl}$ ), 20 had borderline (range 10.3-19.8 ng/dl), 10 had suboptimal (range 20.6-29.7ng/dl) and 14 infants had normal vitamin $D$ levels.

Post treatment levels were available for 17 out of 36 infants with low or borderline levels. Of the 5 infants with initially deficient levels, 3 had normal, 1 had suboptimal and 1 had borderline vitamin D post treatment levels. 8 of the 12 infants with borderline vitamin $\mathrm{D}$ levels had normalized and 4 had suboptimal vitamin D levels post treatment.

These results were comparable to the period when cholecaliferol was used 